\title{
Experimentally Characterization of Coated Cutting Tools Life with Applications to Dies Materials
}

\author{
Ghazi S. Al-Marahleh* \\ Department of Mechanical Engineering, Faculty of Engineering Technology Al Balqa' Applied University, PO Box 15008, 11134 \\ Amman-Jordan
}

\begin{abstract}
The objectives of this study were to investigate the possibility of optimizing the cutting performance for dies materials machining process from hard steel using different coated Cobalt-cemented tungsten carbide (WC-Co) tool inserts (substrates) for finish turning carbon steel (AISI D2). In addition, comparison between uncoated and coated inserts was performed depending on machining speed, feed, and cutting depth without cooling fluids. Chips types and workpiece surface roughness were also studied. As a result we were able to increase cutting tool life which will influence the machining process cost.
\end{abstract}

Key words: Cutting tools, dies forming, hardest conditions, manufacturing.

\section{Introduction}

Increasing demands for high speed and high performance dry machining applications have brought new challenges for the quality of cutting tool materials. High performance dry machining generates severe cutting conditions associated with high temperature and stress within the cutting zone.

In this application of machining hard materials for dies manufacturing in Jordan, the use of advanced coated tools is critical to realize the benefits of high performance machining.

Traditional hard coatings, such as titanium- nitrides (Ti-N) single layer coatings, played an important role in the development stage of new-generation cutting tools in an attempt to improve the wear resistance of cutting and forming tools [1, 2]. A major drawback of Ti-N, however, is its limited resistance to oxidation at high temperature that can be reached during different cutting processes. For this reason, high-temperature chemical stability is a major prerequisite for hard coatings [3].

Recent improvements in the coatings of cutting tools

Corresponding author: Ghazi S. Al-Marahleh, associate professor, research field: Mechanical Engineering. E-mail: g_marahle@yahoo.com. have been achieved by the development of (Ti-Al) $\mathrm{N}$ coatings. (Ti-Al) $\mathrm{N}$ coatings exhibit good wear resistance, high oxidation resistance, high hardness at elevated temperatures, thermal and chemical stability, and low thermal conductivity [4-7]. An extremely important advantage of (Ti-Al)N coatings is that it possesses a high thermal stability due to the formation of a dense, highly adhesive, protective $\mathrm{Al}_{2} \mathrm{O}_{3}$ surface film on the (Ti-Al)N coating in the process of cutting. Such a film prevents diffusion of oxygen into the coating and thus reduces the diffusion wear, one of the major wear mechanisms in cutting tools [8-14]. For this reason (Ti-Al)N has became one of the best solutions as coating material for cutting tools, especially for dry and high speed cutting.

In the current study metal cutting or traditional machining processes (conventional machining processes) were carried on hard die steel materials using different coated Cobalt-cemented tungsten carbide (WC-Co) tool inserts (substrates) for finish turning carbon steel machining tests were carried out on a quenched-tempered steel (AISI D2). In addition, comparison between uncoated and coated inserts was performed depending on machining speed, feed, and cutting depth without cooling fluids. Chips types and 
workpiece surface roughness were also studied. As a result we were able to increase cutting tool life which will influence the machining process cost. Scanning electron microscopy (SEM) were used to measure the cutting tool life and wear of each sample after test.

\section{Experiments}

Tests were conducted on some specimen of materials made from quenched-tempered $\mathrm{Cr}_{4.2} \mathrm{Mo}_{4}$ steel (DIN 1.7225/SAE 4140), which is used widely in several industrial products specially dies industry in Jordan for several applications such as plastic dies, aluminum extrusion dies and many other applications. Die materials hardness was measured as 55 (Rockwellhardness) HRC. Table 1 shows the chemical compositions of die metals. While Fig. 1 and Table 2 show the specification of lath machine name (Ferdinand Cwibert).

Fig 2. Shows work piece and its dimensions (inside diameter $195 \mathrm{~mm}$ and outside $207 \mathrm{~mm}$ ).
Four different cutting tools with different specifications are used, each have been utilized according to certain conditions of cutting operations as follows:

- Depth of cut (mm);

- Feed rate (mm/rev);

- Cooling liquid;

- Cutting speed (m/min);

- Automatic feed rate.

\subsection{Cutting Operation}

A lathe machine is used on one of the edges of specimen No.1 along with $1 \mathrm{~mm}$ cutting depth, $0.1 \mathrm{~mm} / \mathrm{rev}$ feed rate, $23 \mathrm{~m} / \mathrm{min}$ speed of cutting and without any cooling liquids which represents the hardest conditions.

In the second time, another edge for the same specimen along with $1 \mathrm{~mm}$ cutting depth, $0.1 \mathrm{~mm} / \mathrm{rev}$ feed rate, $29 \mathrm{~m} / \mathrm{min}$ speed of cutting and without cooling liquid are used.

Table 1 Chemical Composition of steel (AISI D2) workpiece material.

\begin{tabular}{llllll}
\hline $\mathrm{C} \%$ & $\mathrm{Si} \%$ & $\mathrm{Mn} \%$ & $\mathrm{Cr} \%$ & $\mathrm{~S} \%$ & $\mathrm{~V} \%$ \\
\hline 1.55 & 0.3 & 0.4 & 11.8 & $\mathrm{~W}$ & 0.8 \\
\hline
\end{tabular}

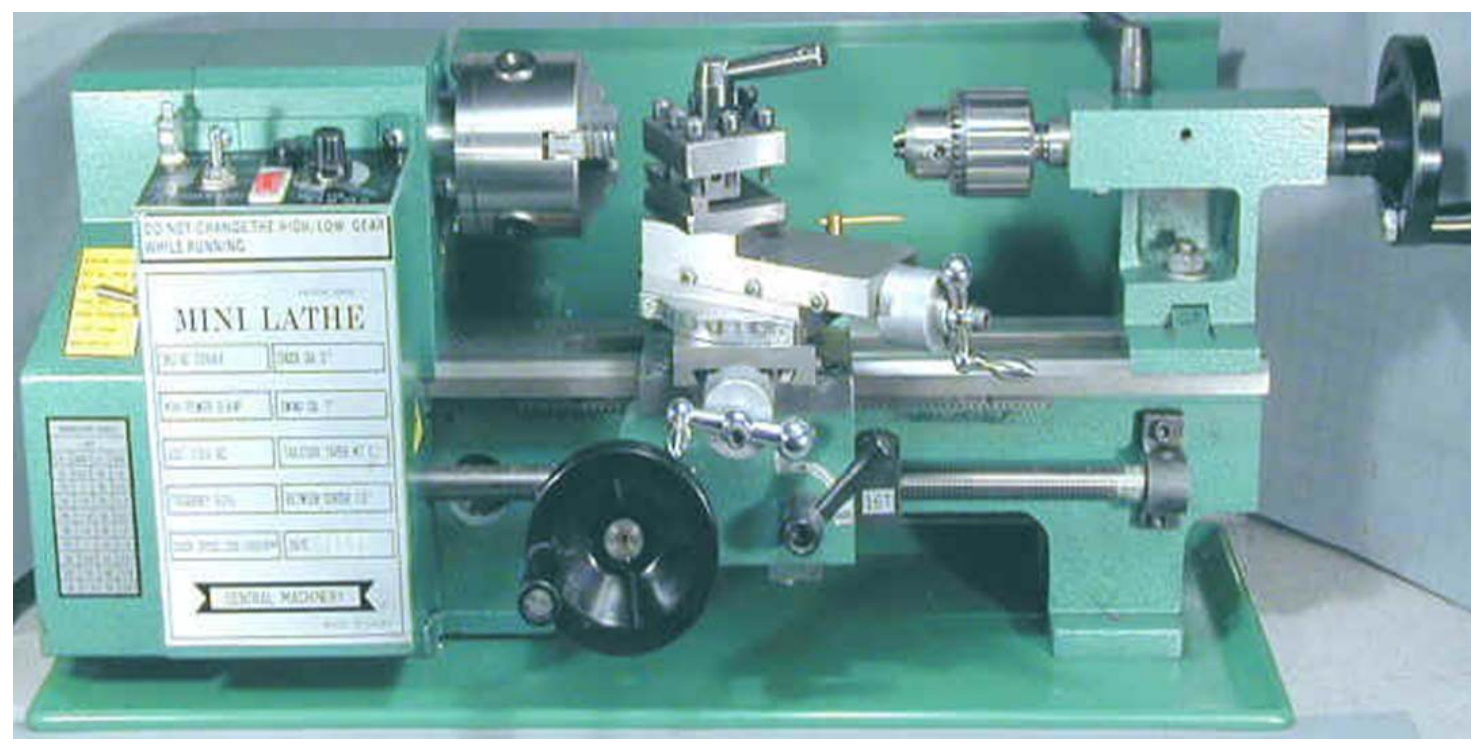

Fig. 1 The specification of lath machine name (Ferdinand cribber).

Table 2 Specifications of centre lathe machine used in experimental tests.

\begin{tabular}{lll}
\hline Spindle speed & Feed rate & Total power \\
\hline $22-2400$ (r.p.m) & $0.08-6.4(\mathrm{~mm} / \mathrm{rev})$ & $6.6(\mathrm{KW})$ for $50(\mathrm{~Hz})$ \\
\hline
\end{tabular}




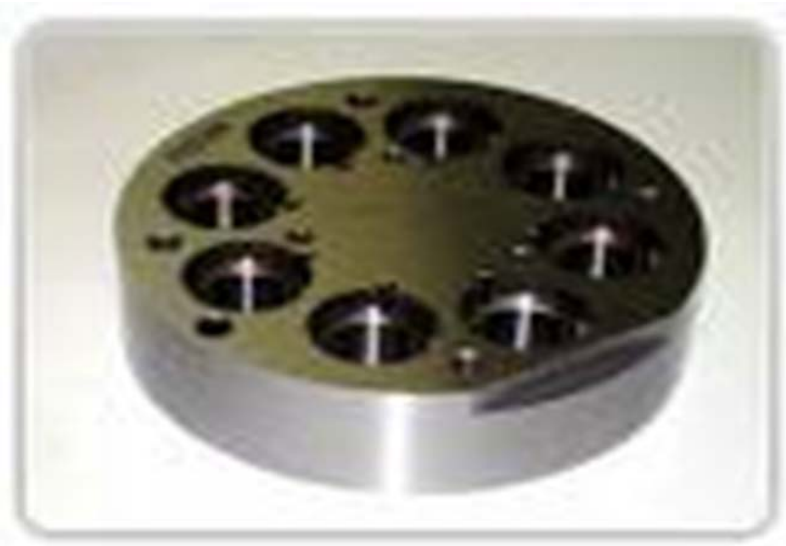

Fig. 2 Photo of work piece test sample.

In the third time, another edge was used for the same specimen along with $0.5 \mathrm{~mm}$ cutting depth, $0.1 \mathrm{~mm} / \mathrm{rev}$ feed rate, $23 \mathrm{~m} / \mathrm{min}$ speed of cutting and without cooling liquid.

In the last, another edge was used for the same specimen along with $0.5 \mathrm{~mm}$ cutting depth, $0.1 \mathrm{~mm} / \mathrm{rev}$ feed rate, $29 \mathrm{~m} / \mathrm{min}$ speed of cutting and without cooling liquid.

In these experiments, the feed rate was completely automatic, and traveled destines for each cutting tool edge was $150 \mathrm{~m}$. Specimen No.2 was implanted but no cutting happened.

The same procedures are repeated for specimen No.3 and No.4 and the following results were obtained as in
Table 3 .

\subsection{Surface Roughness}

After each experiment is done, measure the roughness of the surface being cut using a special purpose roller (flex bar No. 16008). The results are shown in Table 4.

Fig. 7 below shows the relationship between cutting speed $[\mathrm{m} / \mathrm{min}]$ and surface roughness $[\mu \mathrm{m}]$.

\subsection{Examining Cutting tools Wear}

In this step each edge wear after finishing the cutting using digital micrometer is measured and the results are shown in table 5.

Fig. 8 to 10 shows a comparison between the cutting tools with respect to the wear length and cutting depth relation, it can be noticed that tool number four has the maximum wear length while number three has a minimum one.

\subsection{Chip Formation}

The examining tool gives different types of chips given in Table 6.

\section{Results and Discussion}

It is figured out, from the reading that have been took during cutting, that there is a noticeable difference

Table 3 Edge number, kind of chip with cutting speeds and depth of cut.

\begin{tabular}{|c|c|c|c|c|c|c|c|c|}
\hline & & & $\mathrm{T} 1$ & T2 & & $\mathrm{T} 3$ & & $\mathrm{~T} 4$ \\
\hline & & Chips & edge number & \multirow{9}{*}{ 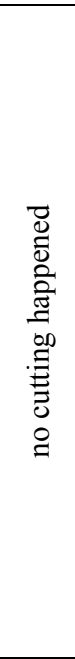 } & chips & edge number & Chips & edge number \\
\hline \multirow[b]{2}{*}{ edge one } & depth of cut $=0.5(\mathrm{~mm})$ & \multirow[b]{2}{*}{1} & $\multirow{2}{*}{6}_{2}^{2}$ & & \multirow[b]{2}{*}{4} & & \multirow[b]{2}{*}{8} & \multirow{2}{*}{$6^{10}$} \\
\hline & speed of cut $=29(\mathrm{~m} / \mathrm{min})$ & & & & & $1 \mathrm{~A}$ & & \\
\hline \multirow[b]{2}{*}{ edge two } & depth of cut $=0.5(\mathrm{~mm})$ & \multirow[b]{2}{*}{1} & \multirow{2}{*}{$\mathrm{SW}_{3}^{2}$} & & \multirow[b]{2}{*}{6} & & \multirow[b]{2}{*}{10} & \\
\hline & speed of cut $=23(\mathrm{~m} / \mathrm{min})$ & & & & & 08 & & \\
\hline \multirow[b]{2}{*}{ edge three } & depth of cut $=1(\mathrm{~mm})$ & \multirow[b]{2}{*}{3} & \multirow{2}{*}[\sigma_{3}^{2}]{$_{3}$} & & \multirow[b]{2}{*}{7} & & \multirow[b]{2}{*}{11} & \\
\hline & speed of cut $=23(\mathrm{~m} / \mathrm{min})$ & & & & & 08 & & \\
\hline \multirow[b]{2}{*}{ edge four } & depth of cut $=1(\mathrm{~mm})$ & \multirow[b]{2}{*}{2} & \multirow{2}{*}{$\mathrm{BN}_{2}^{2}$} & & \multirow[b]{2}{*}{5} & & \multirow[b]{2}{*}{9} & \multirow{2}{*}{$6^{1010}$} \\
\hline & speed of cut $=29(\mathrm{~m} / \mathrm{min})$ & & & & & $1 \mathrm{~A}$ & & \\
\hline
\end{tabular}




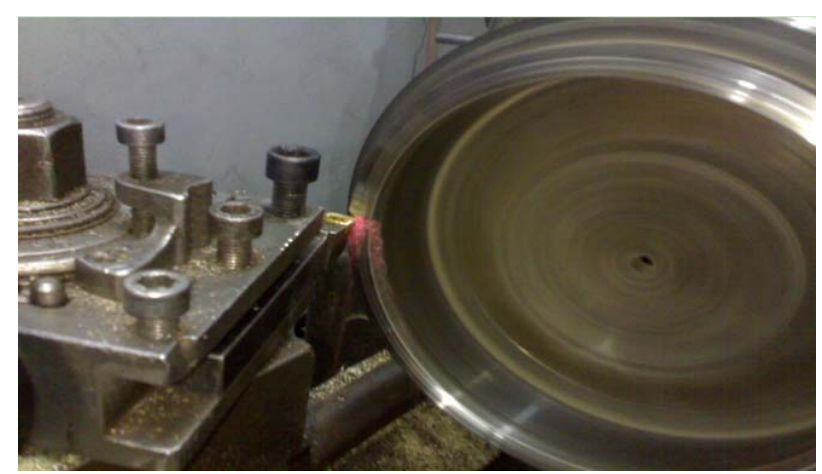

Fig. 3 Photo of machining tool No.1 during cutting process.

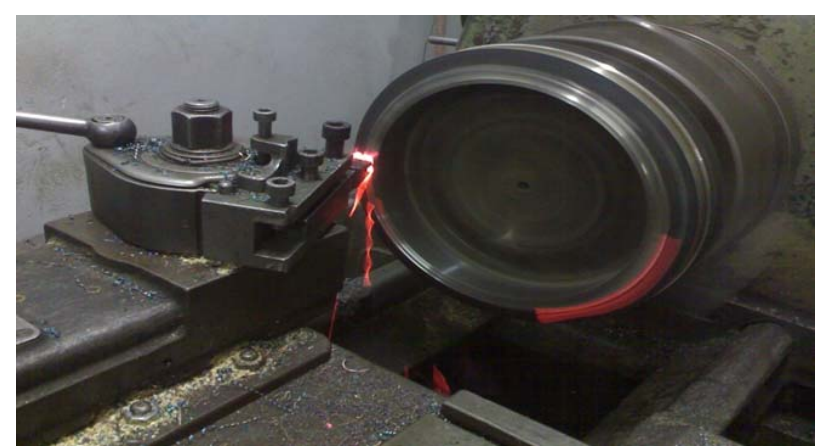

Fig. 4 Photo of machining tool No.2 during cutting process.

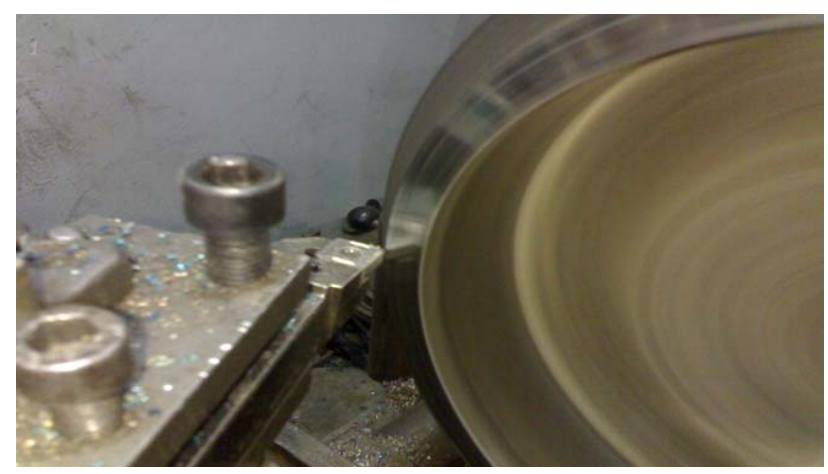

Fig. 5 Photo of machining tool No.3 during cutting process.

between each cutting tool regarding the following items: shape of formed surface, shape of chips and the wear done on each tool, and there is a difference between each edge for the same cutting tool depending on various conditions (Figs. (11-13) shows SEM photos of some of the samples with sever wear.

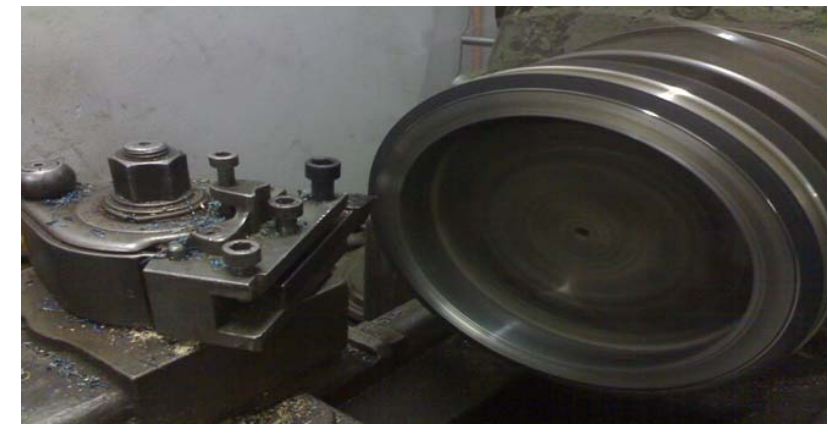

Fig. 6 Photo of machining tool No.4 during cutting process.

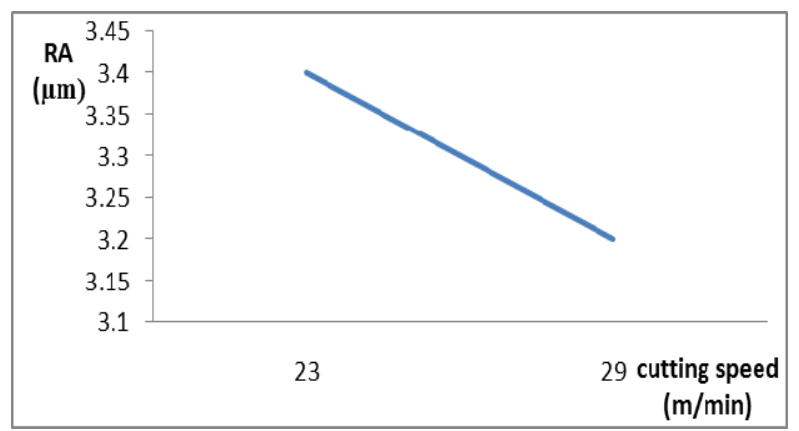

Fig 7 Cutting speed $(\mathrm{m} / \mathrm{min})$ vs surface roughness $(\mu \mathrm{m})$.

\subsection{Cutting Tool No.1}

When applying depth of cut $0.5 \mathrm{~mm}$ along with $23 \mathrm{~m} / \mathrm{min}$, we have come out with $\mathrm{Ra}=3.4 \mu \mathrm{m}$ but when applying $29 \mathrm{~m} / \mathrm{min}$ with depth of cut remain the same, we have come out with $\mathrm{Ra}=3.2 \mu \mathrm{m}$. This lead us to a simple conclusion; that when we increase speed of cut, surface roughness decrease. For the same parameters we get short helical broken chips and c-type/3-type broken chips, respectively. This shows us that when we increase speed of cut, we get the desired chips. When applying depth of cut $0.5 \mathrm{~mm}$ along with $23 \mathrm{~m} / \mathrm{min}$, we have come out with wear length $=(0.42$ $\times 10^{3} \mu \mathrm{m}$ ) but when applying $29 \mathrm{~m} / \mathrm{min}$ with depth of cut remain the same, we have come out with wear length $=\left(0.48 \times 10^{3} \mu \mathrm{m}\right)$. This lead us to a simple conclusion; that when we increase speed of cut, wear

Table 4 Surface Roughness values at different machining conditions for tools with coated inserts.

\begin{tabular}{|c|c|c|c|c|c|c|c|c|c|}
\hline \multicolumn{2}{|l|}{ Feed rate $(\mathrm{mm} / \mathrm{rev})$} & \multicolumn{4}{|c|}{0.1} & \multicolumn{4}{|c|}{0.1} \\
\hline \multicolumn{2}{|l|}{ Depth of cut (mm) } & \multicolumn{4}{|c|}{0.5} & \multicolumn{4}{|c|}{1} \\
\hline \multirow{2}{*}{\multicolumn{2}{|c|}{ Tool No* }} & $\mathrm{T} 1$ & $\mathrm{~T} 2$ & T3 & $\mathrm{T} 4$ & T1 & $\mathrm{T} 2$ & T3 & $\mathrm{T} 4$ \\
\hline & & \multicolumn{8}{|c|}{ Surface roughness $(\mathrm{Ra})(\mu \mathrm{m})$} \\
\hline \multirow{2}{*}{ Cutting speed $\mathrm{m} / \mathrm{min}$} & 23 & 3.4 & - & 1.6 & 2.8 & 6.3 & - & 3.6 & 5 \\
\hline & 29 & 3.2 & - & 1.4 & 2.6 & 6 & - & 3.5 & 4.8 \\
\hline
\end{tabular}


Table 5 Wear length in different edges of cutting tool.

\begin{tabular}{|c|c|c|c|c|c|c|c|}
\hline & \multicolumn{2}{|r|}{$\mathrm{T} 1$} & \multirow{2}{*}{$\frac{\mathrm{T} 2}{\pi}$} & \multicolumn{2}{|r|}{$\mathrm{T} 3$} & \multicolumn{2}{|r|}{$\mathrm{T} 4$} \\
\hline & edge & wear length $\left(\mu \mathrm{m}^{*} 10^{\wedge} 3\right)$ & & edge & wear length $\left(\mu \mathrm{m}^{*} 10^{\wedge} 3\right)$ & edge & wear length $\left(\mu \mathrm{m}^{*} 10^{\wedge} 3\right)$ \\
\hline depth of cut = $1(\mathrm{~mm})$ & \multirow{2}{*}{2} & \multirow{2}{*}{0.79} & \multirow{8}{*}{ 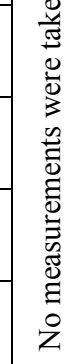 } & 08 & 069 & A1 & 127 \\
\hline speed of cut $=23(\mathrm{~m} / \mathrm{min})$ & & & & 00 & 0.09 & A1 & 1.21 \\
\hline depth of cut = $1(\mathrm{~mm})$ & \multirow{2}{*}{3} & \multirow{2}{*}{0.83} & & \multirow{2}{*}{ A1 } & \multirow{2}{*}{0.8} & \multirow{2}{*}{02} & \multirow{2}{*}{1.44} \\
\hline speed of cut $=29(\mathrm{~m} / \mathrm{min})$ & & & & & & & \\
\hline depth of cut $=0.5(\mathrm{~mm})$ & \multirow{2}{*}{2} & \multirow{2}{*}{0.42} & & \multirow{2}{*}{08} & \multirow{2}{*}{0.33} & \multirow{2}{*}{02} & \multirow{2}{*}{0.95} \\
\hline speed of cut $=23(\mathrm{~m} / \mathrm{min})$ & & & & & & & \\
\hline depth of cut $=0.5(\mathrm{~mm})$ & \multirow{2}{*}{3} & \multirow{2}{*}{0.48} & & \multirow{2}{*}{ A1 } & \multirow{2}{*}{0.38} & \multirow{2}{*}{ A1 } & \multirow{2}{*}{0.98} \\
\hline speed of cut $=29(\mathrm{~m} / \mathrm{min})$ & & & & & & & \\
\hline
\end{tabular}

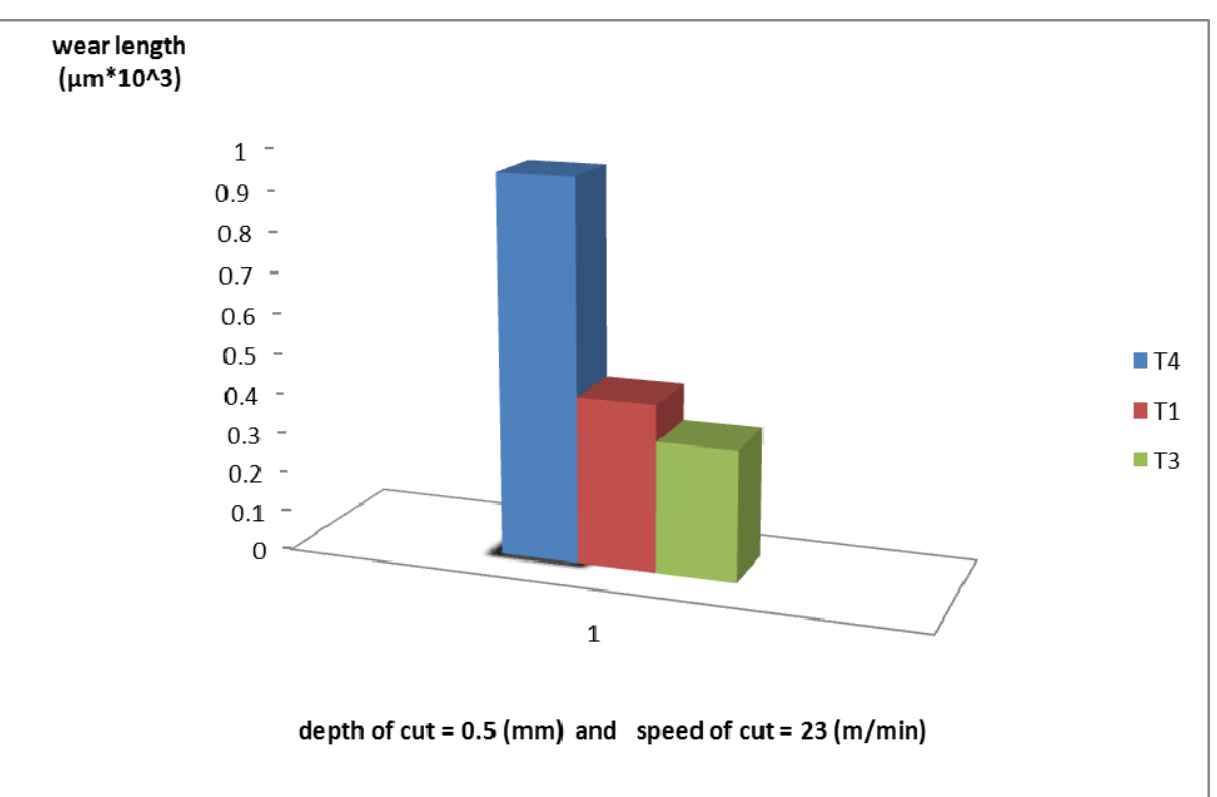

Fig. 8 Wear length $\left(\mu \mathrm{m}^{*} 10^{\wedge} 3\right)$ vs depth of cut $=0.5(\mathrm{~mm})$ and speed of cut $=23(\mathrm{~m} / \mathrm{min})$.

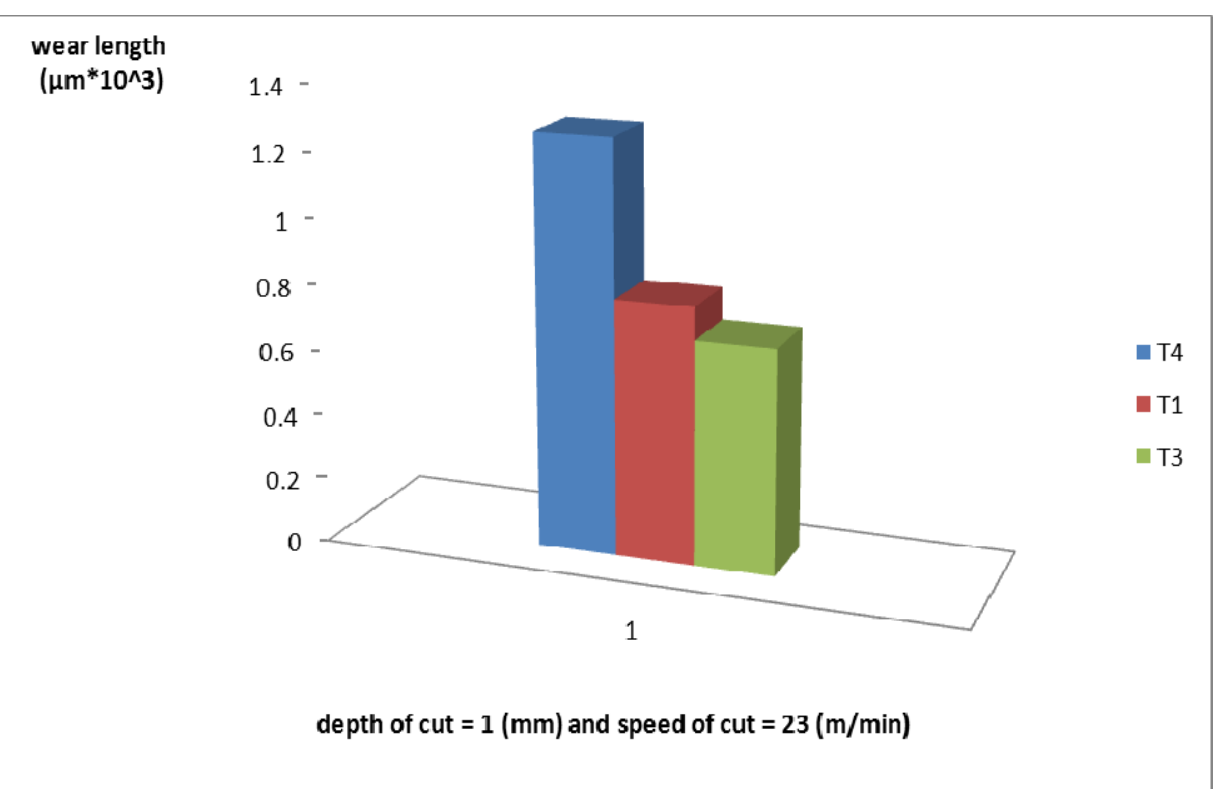

Fig. 8 Wear length $\left(\times 10^{3} \mu \mathrm{m}\right)$ vs depth of cut $=1(\mathrm{~mm})$ and speed of cut $=23(\mathrm{~m} / \mathrm{min})$. 


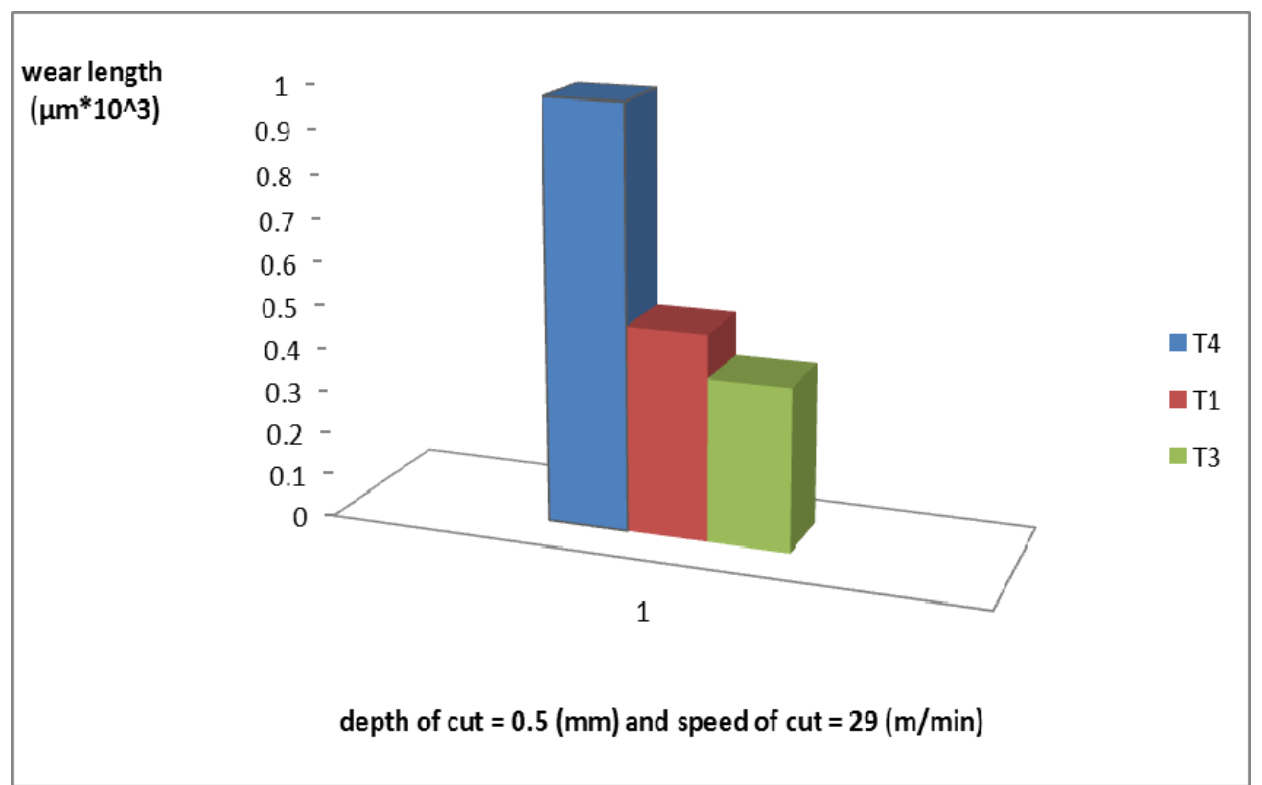

Fig. 9 Wear length $\left(\times 10^{3} \mu \mathrm{m} 3\right)$ vs depth of cut $=0.5(\mathrm{~mm})$ and speed of cut $=29(\mathrm{~m} / \mathrm{min})$.

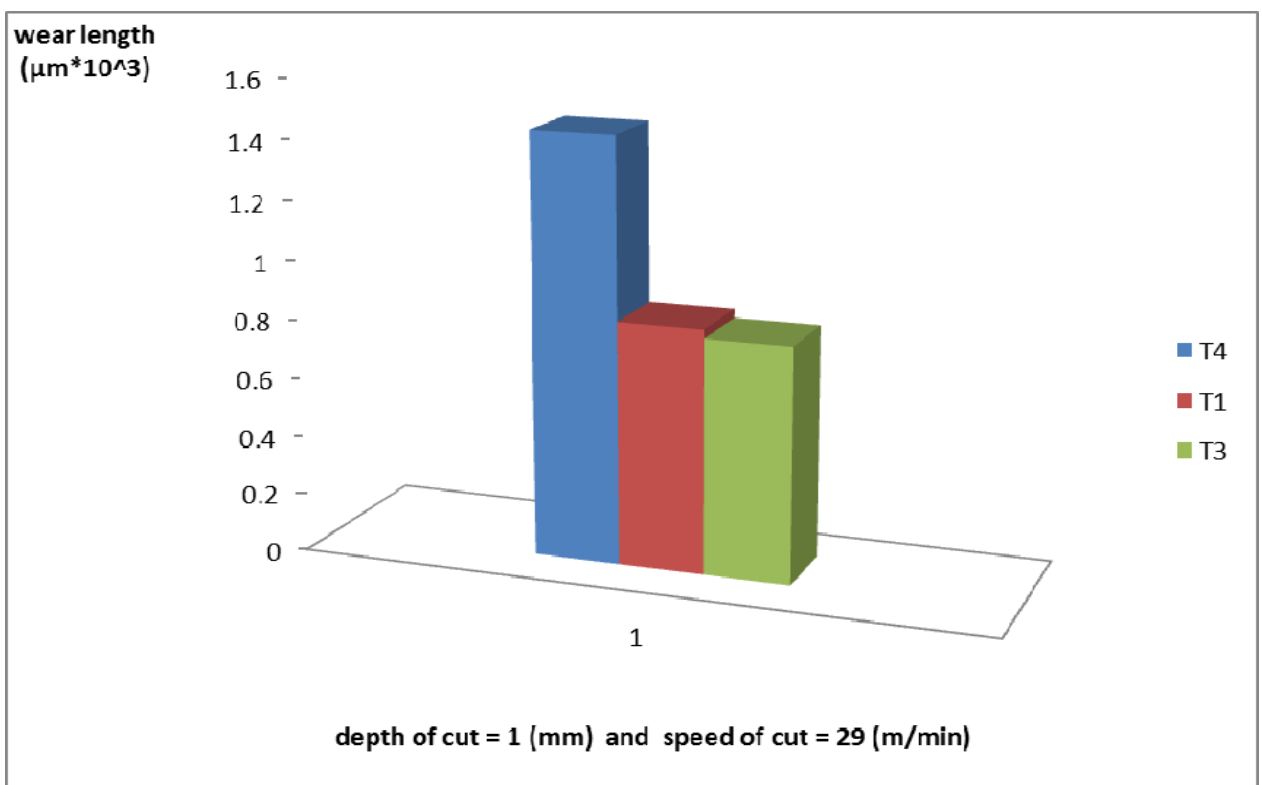

Fig. 10 Wear length $\left(\times 10^{3} \mu \mathrm{m}\right)$ vs depth of cut $=1(\mathrm{~mm})$ and speed of cut $=29(\mathrm{~m} / \mathrm{min})$.

length increases. When applying depth of cut $1.0 \mathrm{~mm}$ along with $23 \mathrm{~m} / \mathrm{min}$, we have come out with $\mathrm{Ra}=6.3$ $\mu \mathrm{m}$ but when applying $29 \mathrm{~m} / \mathrm{min}$ with depth of cut remain the same, we have come out with $\mathrm{Ra}=6.0 \mu \mathrm{m}$. This lead us to a simple conclusion; that when we increase speed of cut, surface roughness decrease. For the same parameters we get long helical broken chips and c-type/3-type broken chips, respectively. This shows us that when we increase speed of cut, we get the desired chips. When applying depth of cut
$1.0 \mathrm{~mm}$ along with $23 \mathrm{~m} / \mathrm{min}$, we have come out with wear length $=\left(0.79 \times 10^{3} \mu \mathrm{m}\right)$ but when applying 29 $\mathrm{m} / \mathrm{min}$ with depth of cut remain the same, we have come out with wear length $=\left(0.83 \times 10^{3} \mu \mathrm{m}\right)$.This lead us to a simple conclusion; that when we increase speed of cut, wear length increases.

\subsection{Cutting Tool No.2}

Slight ignorant cutting is done, no measurements were taken. 
Table 6 Types of formed chips.

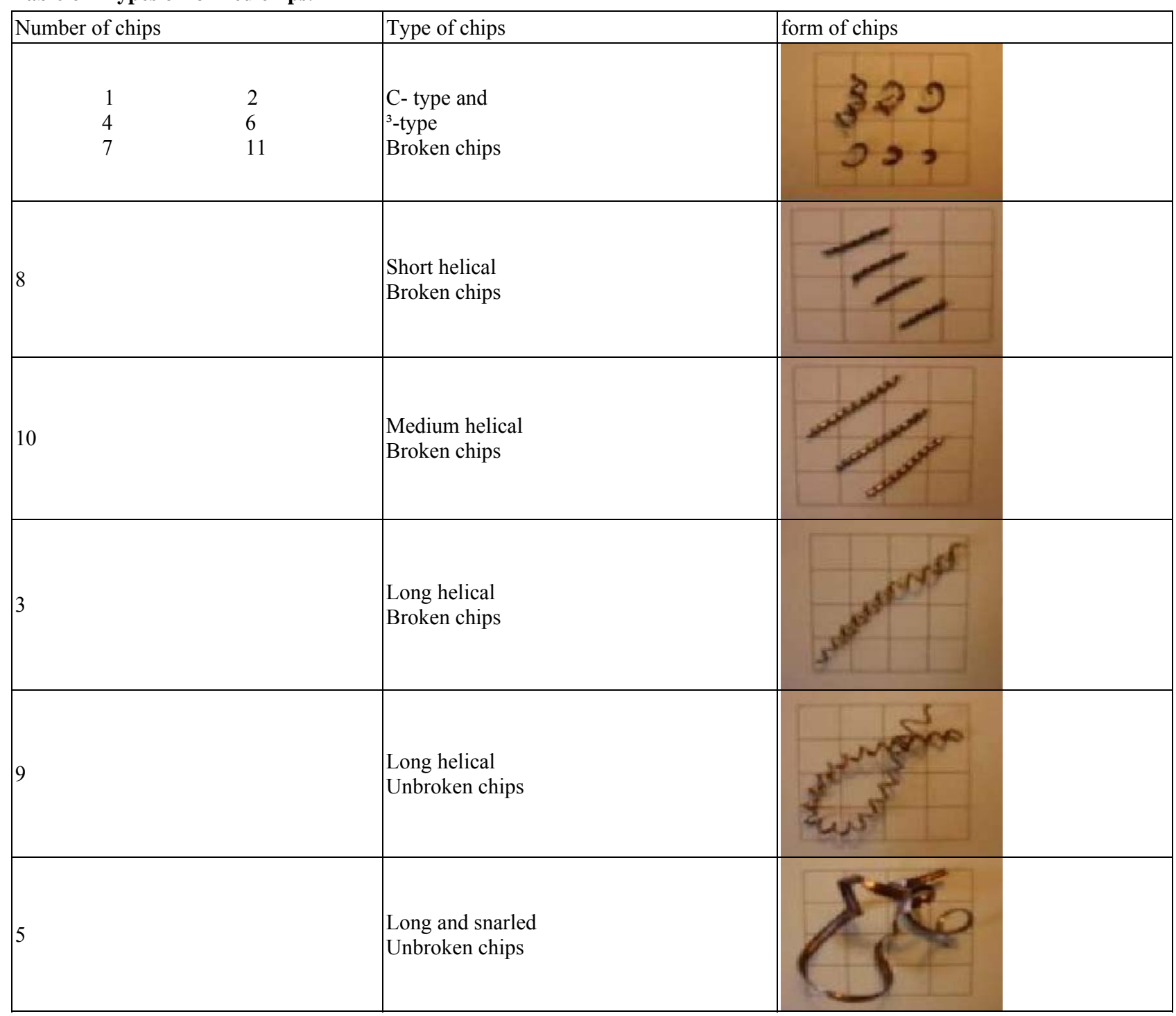

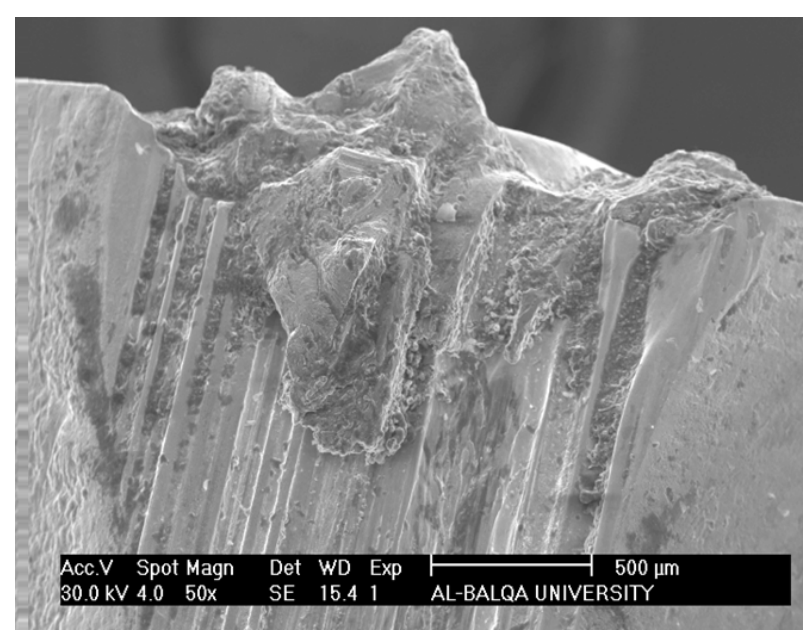

Fig. 11 SEM images of coated tool inserts No.3 after machining at $29 \mathrm{~m} \mathrm{~min}^{-1}$.

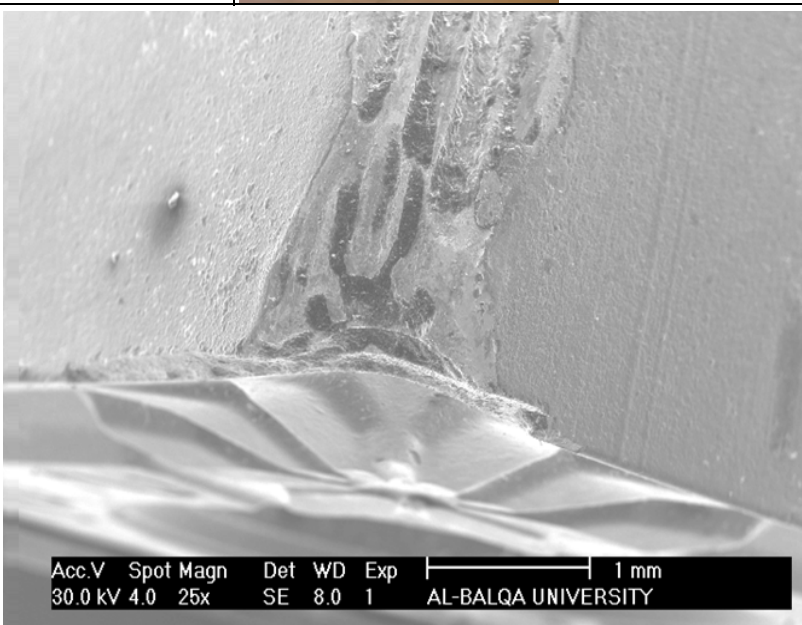

Fig. 12 SEM images of coated tool inserts No.1 after machining at $29 \mathrm{~m} \mathrm{~min}^{-1}$. 


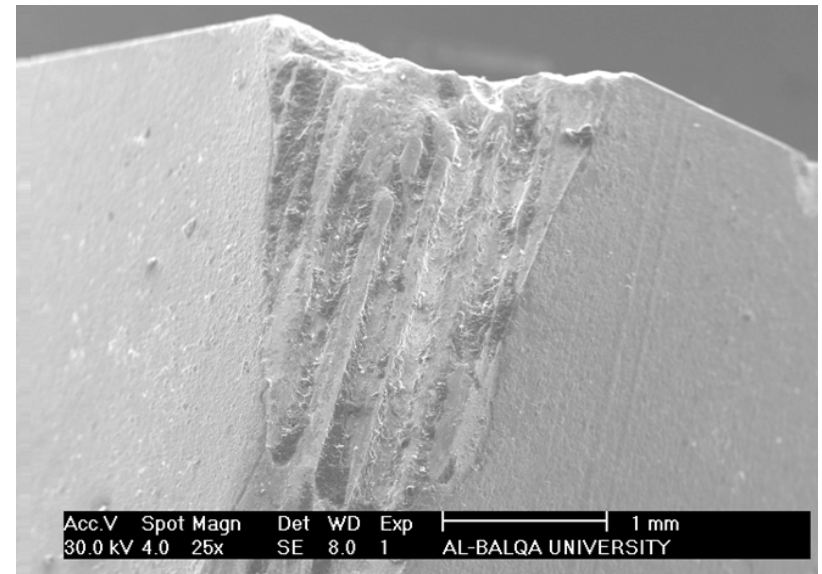

Fig. 13 SEM images of coated tool inserts No.4 after machining at $29 \mathrm{~m} \mathrm{~min}^{-1}$.

\subsection{Cutting Tool No.3}

When applying depth of cut $0.5 \mathrm{~mm}$ along with $23 \mathrm{~m} / \mathrm{min}$, we have come out with $\mathrm{Ra}=1.6 \mu \mathrm{m}$ but when applying $29 \mathrm{~m} / \mathrm{min}$ with depth of cut remain the same, we have come out with $\mathrm{Ra}=1.4 \mu \mathrm{m}$. This lead us to a simple conclusion; that when we increase speed of cut, surface roughness decrease. For the same parameters we get short helical broken chips and c-type/3-type broken chips, respectively. This shows us that when we increase speed of cut, we get the desired chips. When applying depth of cut $0.5 \mathrm{~mm}$ along with $23 \mathrm{~m} / \mathrm{min}$, we have come out with wear length $=(0.33$ $\times 10^{3} \mu \mathrm{m}$ ) but when applying $29 \mathrm{~m} / \mathrm{min}$ with depth of cut remain the same, we have come out with wear length $=\left(0.38 \times 10^{3} \mu \mathrm{m}\right)$. This lead us to a simple conclusion; that when we increase speed of cut, wear length increases. When applying depth of cut $1.0 \mathrm{~mm}$ along with $23 \mathrm{~m} / \mathrm{min}$, we have come out with $\mathrm{Ra}=3.6$ $\mu \mathrm{m}$ but when applying $29 \mathrm{~m} / \mathrm{min}$ with depth of cut remain the same, we have come out with $\mathrm{Ra}=3.5 \mu \mathrm{m}$. This lead us to a simple conclusion; that when we increase speed of cut, surface roughness decrease. For the same parameters we get long and snarled unbroken chips and c-type/3-type broken chips, respectively. This shows us that when speed of cut is increased, the desired chips are formed. Generally, unbroken long chips are not desired. When applying depth of cut 1.0 $\mathrm{mm}$ along with $23 \mathrm{~m} / \mathrm{min}$, we have come out with wear length $=\left(0.69 \times 10^{3} \mu \mathrm{m}\right)$ but when applying $29 \mathrm{~m} / \mathrm{min}$ with depth of cut remain the same, the wear length will be $=\left(0.80 \times 10^{3} \mu \mathrm{m}\right)$. This lead us to a simple conclusion; that when we increase speed of cut, wear length increases.

\subsection{Cutting Tool No.4}

When applying depth of cut $0.5 \mathrm{~mm}$ along with $23 \mathrm{~m} / \mathrm{min}$, we have come out with $\mathrm{Ra}=2.8 \mu \mathrm{m}$ but when applying $29 \mathrm{~m} / \mathrm{min}$ with depth of cut remain the same, we have come out with $\mathrm{Ra}=2.6 \mu \mathrm{m}$. This lead us to a simple conclusion; that when we increase speed of cut, surface roughness decrease. For the same parameters we get medium helical broken chips and short helical broken chips, respectively. This shows us that when we increase speed of cut, we get the desired chips. When applying depth of cut $0.5 \mathrm{~mm}$ along with $23 \mathrm{~m} / \mathrm{min}$, we have come out with wear length $=(0.95$ $\times 10^{3} \mu \mathrm{m}$ ) but when applying $29 \mathrm{~m} / \mathrm{min}$ with depth of cut remain the same, we have come out with wear length $=\left(0.98 \times 10^{3} \mu \mathrm{m}\right)$. This lead us to a simple conclusion; that when we increase speed of cut, wear length increases. When applying depth of cut $1.0 \mathrm{~mm}$ along with $23 \mathrm{~m} / \mathrm{min}$, we have come out with $\mathrm{Ra}=$ $5.0 \mu \mathrm{m}$ but when applying $29 \mathrm{~m} / \mathrm{min}$ with depth of cut remain the same, we have come out with $\mathrm{Ra}=4.8 \mu \mathrm{m}$. This lead us to a simple conclusion; that when we increase speed of cut, surface roughness decrease. For the same parameters we get long helical unbroken chips and c-type/3-type broken chips, respectively. This shows us that when we increase speed of cut, we get the desired chips. Generally, unbroken long chips are not desired. When applying depth of cut $1.0 \mathrm{~mm}$ along with $23 \mathrm{~m} / \mathrm{min}$, we have come out with wear length $=\left(1.27 \times 10^{3} \mu \mathrm{m}\right)$ but when applying $29 \mathrm{~m} / \mathrm{min}$ with depth of cut remain the same, we have come out with wear length $=\left(1.44 \times 10^{3} \mu \mathrm{m}\right)$. This lead us to a simple conclusion; that when we increase speed of cut, wear length increases.

\section{Conclusions}


The discussions of the best cutting tool have made by examining a number of inserts under specific conditions and we get theses conclusion:

(1) Cutting tool No.1:

It has the highest surface roughness in all cases that, depth of cut $0.5 \mathrm{~mm}$ and speed of cut $23 \mathrm{~m} / \mathrm{min}$. And the highest surface roughness at depth of cut $1 \mathrm{~mm}$ and speed of $29 \mathrm{~m} / \mathrm{min}$.

It has a medium wear length.

(2) Cutting tool No.2:

There is no cutting happened so it is very highly wear because it is coated by a layer of carbon that has a low friction coefficient.

(3) Cutting tool No.3:

It has the lowest surface roughness in depth of cut $0.5 \mathrm{~mm}$ and speed of cut $23 \mathrm{~m} / \mathrm{min}$. And the highest surface roughness at depth of cut $1 \mathrm{~mm}$ and speed of 29 $\mathrm{m} / \mathrm{min}$.

It has a lowest wear length.

(4) Cutting tool No 4:

It has the medium surface roughness in all cases that, depth of cut $0.5 \mathrm{~mm}$ and speed of cut $23 \mathrm{~m} / \mathrm{min}$. And the highest surface roughness at depth of cut $1 \mathrm{~mm}$ and speed of $29 \mathrm{~m} / \mathrm{min}$.

It has a lowest wear length.

(5) the uses of a specific kind of cutting tool depends on the application of the products like surface roughness of theme and the hardness of metal used.
(6) coating the cutting tools improve theme; it becomes higher thermal resistance, long life, higher wear resistance and higher mechanical characteristic.

\section{References}

[1] Mills, B., and Redford, A. H. 1983. "Tool Materials, Machinibility of Engineering Materials.” MC. Graw Hill 59-92.

[2] Boothroyd, G. 1975. "Fundamentals of Metal Machining and Machine Tool." MC. Graw hill.

[3] Ostwald, P. F. 1996. Manufacturing Process and Systems. New York: John Wiley.

[4] Nargpal, G. R. 1996. Machine Tool Engineering. Romesh Chander Khanna.

[5] Shaw, M. C. 1984. Metal Cutting Principles Oxford: Clarendon Press.

[6] Singh, R. 2006. Introduction to Basic Manufacturing Processes and Workshop Technology. New Age International (P) Ltd., Publishers.

[7] Jack, H. Manufacturing Processes. Copyright (C) 1993-2001.

[8] McIntyre, D., Greene, J. E., Hakansson, G., Sundgren, J. E., and Munz, W.D. 1990. J. Appl. Phys. 67: 1542.

[9] Han, J. G., Yoon, J. S., Kim, H. J., and Song, K. 1996. Surf. Coat. Technol. 86-87: 82-7.

[10] Wang, Y. 1997. Surf. Coat. Technol. 94-95: 60-63.

[11] Wang, D. Y., Chang, C. L., Wong, K. W., Li, Y. W., and Ho, W.Y. 1999. Surf. Coat. Technol. 120-121: 388-394.

[12] Kimura, A., Hasegawa, H., Yamada, K., and Suzuki, T. 2000. J. Mater. Sci. Lett. 19: 601-2.

[13] Kimura, A., Murakami, T., Yamada, K., and Suzuki, T. 2001. Thin Solid Films 382: 101-5.

[14] Prengel, H. G., Santhanam, A. T., Penich, R. M., Jindal, P. C., and Wendt, K.H. 1997. Surf. Coat. Technol. 94-95: 597-602. 